\title{
Academic Performance of Students who Create and Use Outlines
}

\author{
Shara May T. Espinol \\ University of Batangas, Philippines
}

\begin{abstract}
Technology introduced gadgets such as computers, laptops, and mobile phones to help people in their tasks. For the students, these things had been replacing the use of notebooks and other writing materials in the past decades. There had been conflicting pieces of evidence however about how it affects the learners' attitude and perception of the learning process. This research was conducted to review if making outlines is still a great way to help students learn or should all students just rely on their gadgets. It also aimed to know if the task helps the students to think highly of themselves and be more confident about their studies. The results showed that there is no significant difference in the academic performance of the students who were required to outline compared to those who did not outline. However, data revealed that students perceived that they can do better and perform better in class when making outlines. The extraneous variables at play in this field study may be the reason for the results obtained. This goes to show that there is still a need to review teaching pedagogies and classroom management techniques to incorporate study habits that are effective based on the needs of the students.
\end{abstract}

\section{Introduction}

Since the time that the students have been the center of the educational system, educators use, developed, modified, and implemented different teaching strategies to help them succeed. With the development of technology, acquiring information has been easier. In the olden days, people used dictionaries and copied the information they needed by hand. Books are hard to come by and photocopies are costly. Those were the days when students stayed in the libraries to study. They read the books there and copy the lectures by hand, either verbatim or by outlining. Whatever they have read on the books is transferred into paper, usually in an outline, so that they get the gist of the information and at the same time, save space on their notebooks and energy from writing. Today, students could easily download all types of information online and print at the comfort of their own homes. They could even save it on their devices for reading later. Students simply flick through their devices to access information, lectures, and learning materials when attending classes. Ideally, it is supposed to help them focus on listening instead of having to divide their attention into writing and listening. However, do these improvements help students to learn what they need?

On a day-to-day basis, the researcher observed how college students would simply take pictures of the lecture on their mobile phones instead of copying them. They come to school with a very small bag containing just their wallets and cell phone. Some of them do not even bring pens anymore. It seems the only remaining task inside the classroom is for them to absorb what they can hear from the teacher and what they can get from their gadgets. They can even easily and quickly search for answers to their questions online. And it is somehow puzzling that even with the ease in acquiring information the grades of the students are still only average for most of them and even low for several students in the major subjects. In an international setting, Eberly Center of Carnegie Mellon University [3] pointed out that college students have poor writing skills due to the lack of experience in writing sophisticated material in the earlier years of education. This was supported by several citations stating that poor writing skills also reflect the inability to organize information, weak arguments, and feeble reasoning. This is because writing skills are tied to reading comprehension and analytical skills. It was stated that during the high school years, some students were merely asked to write opinions and definitions instead of analyzing text, writing reviews, and writing critique papers. Does this mean technology failed in supporting the students to achieve academic ease and excellence?

Considering these views about technology-filled classroom set-ups, should reverting to traditional study habits be considered? Different study habits are being used by the students and prescribed by the teachers for better learning. It is the goal of every academic institution to cater to the unique learning needs of the students. One of the most effective habits that students used in the past is outlining the lesson and taking down notes. Purdue Online Writing Lab [11] defined the practice of outlining a helpful way to show logical relationships of 
information. This is a very helpful step when writing a paper such as an essay or a thesis. Hansen [7] included being organized and note-taking in his list of tips to get good or better grades in college. The notes provide a clue as to where the instructors focused on the lesson. These notes may also be organized in an outline, later on, to help students in recalling what had just been discussed in class.

In agreement, Smith [12] stated that outlining could help the students to organize their thoughts and to remember their lessons. Whenever students study, they are encouraged to make outlines so that they can arrange their thoughts in a way that they could easily recall or remember later. Huge concepts may be broken down into bits that are easier to recall and ideas could easily be connected in ways that the students could comprehend. The outline could range from containing keywords and phrases to short sentences and paragraphs. The flexibility of presenting information is also a great help for the students. They may even apply a bit of creativity by using maps and graphs along with their keywords.

Outlining may be done in several ways, depending on the person who will use it. Some outlines are done while simultaneously listening to the lectures of the teachers. This practice is also called note-taking. Outlining is one method for note-taking according to Wong as cited in Missouri State University [9]. This is considered the most common and simplest note-taking strategy used by college students. It was discussed in an article in MindTools [8] that effective note-taking leads to better listening and recording skills which is an important part of working as a professional in the future. The task of listening to lectures while taking-down notes also enhance the ability of the learners to focus. In addition to this, the practice also prevents students from being distracted by digital variables. When taking down notes or outlining the verbal stimuli presented during class discussion, the students are trained to focus only on specific variables and ignore the others. Several senses and cognitive processes are tapped by this practice. Since the task allows them to experience the information several times - visual, auditory, and kinesthetic - it allows them to retain the information longer.

The effectiveness of note-taking through the use of outlines may depend on the course or subject being taken. When you are studying law, with all the laws and facts that you need to understand and memorize, outlining is necessary. The article of Warren [13] summarized the importance of note-taking for law students. There are so many reasons why one should make their outline of the lessons. It includes being able to format your outline based on the subject, you will know what you need to include, it will help you memorize things, and you can practice your writing skills.

Writing down ideas and concepts for the better recall is a great study habit for students at any level. In places where paper, teacher motivation, and counseling are scarce, students could only rely upon themselves and their ability to simplify their lessons. In the following studies, researchers related outlines and note-taking with the class performance of the students. This is often reflected in their academic achievement or their grades.

In comparing the learners who used note-taking from those who use modern technology, a comparative study cited in the article of Doubek [5] suggested that students who take down notes tend to perform better in class than those who used their gadgets. The experiment showed that note-takers remember information better as well. This article also categorized note-taking as generative and non-generative. Generative note-taking pertains to transforming information by paraphrasing or summarizing what is heard in the process of writing it down. Non-generative note-taking simply means writing what is heard. And regardless of the note-taking category, those who used notes instead of recording on laptops and gadgets still did better at the task.

Teachers and students in the study of Haghverdi, Biria, and Karimi [6] agreed that note-taking strategies have a positive effect on academic achievement. The same result was achieved by Al-Ashkar [1] when he related note-taking strategies with the academic achievement of students in English and TEFL majors. He found out that a lot of students engage in note-taking and see it as an effective tool when studying. It also helps them improve their listening and writing skills. It was highly recommended that note-taking strategies are included in designing curriculums and that teachers be trained when it comes to note-taking as well. Studies with respondents from students with different courses seem to provide the same results. Chen [4] found out that in-class note-taking could predict the academic performance of Taiwanese psychology students in a memory test. The study stated that the participants had a poor quality of lecture notes and that they scored low on the lesson about memory.

Going back to the question of whether technology or traditional hand-written notes are more effective in learning, several studies also suggest that taking notes by hand instead of using laptops or other gadgets is more effective in increasing academic achievement. Mueller and Oppenheimer [10] found out that even if laptops are also useful in taking notes, it is different from writing them down by hand. Laptop users tend to do poorly when answering conceptual questions compared to those who resort to handwritten notes. The study also suggests that this is because laptop users tend to encode lectures verbatim instead of constructing their thoughts and writing them in a way that they could easily recall and understand the information. However, another study by Beck [2] found that there is no significant difference in the test scores of students who took notes by hand and those who did use laptops. The results were the same for 
the immediate and the delayed tests. This still shows that there is no advantage to using technology when it comes to taking notes.

Making an outline or taking down notes is also one of the requirements being asked from Psychology students on some of their major subjects starting the academic year 2016-2017. The researcher wanted to evaluate the efficiency of this method by conducting this research. It was hypothesized that there is a significant difference in the academic performance between batch 2015-2016 and batch 2016-2017.

Taking these factors at hand, the researcher conducted this study to see if the college students of the university will also show better learning capacity when taking down notes. Specifically, this researcher formulated the following statement of the problem: (1) what is the level of academic efficiency of the students who outline the lesson and those who did not; (2) is there a significant difference in the grades of the students who were required to outline those who did not outline; and (3) what intervention may be applied in the teaching strategy of teachers based on the results of the study.

\section{Methods}

The researcher used a descriptive-comparative design which was also supported by a qualitative method done by using an unstructured interview in the form of guide questions. The researcher constructed a survey to measure the perception of the students about making an outline and its effects on their studies. This instrument was validated by experts in the field of education and research. It is a 4-point scale which is all positively stated.

The researcher also compared the grades of the students on one subject on the grades of the students from the previous batch who were not required to outline by using a t-test for paired samples. A total of 23 students from each batch were paired and their grades were compared.

\section{Results}

Considering the general goal of finding out if requiring the students to outline will improve their academic performance; data were gathered and analyzed qualitatively and quantitatively. The descriptive result presented through the composite mean is in Table 1.

Table 1. Perceived academic efficiency from making an outline

\begin{tabular}{|c|c|c|}
\hline Item & $\begin{array}{c}\text { Composite } \\
\text { Mean }\end{array}$ & $\begin{array}{c}\text { Verbal } \\
\text { Interpretation }\end{array}$ \\
\hline 1 & 3.72 & Efficient \\
\hline 2 & 3.50 & Efficient \\
\hline
\end{tabular}

\begin{tabular}{|c|c|c|}
\hline 3 & 3.72 & Efficient \\
\hline 4 & 3.44 & Efficient \\
\hline 5 & 3.61 & Efficient \\
\hline 6 & 3.67 & Efficient \\
\hline 7 & 3.54 & Efficient \\
\hline 8 & 3.78 & Efficient \\
\hline 9 & 3.81 & Efficient \\
\hline 10 & 3.70 & Efficient \\
\hline TOTAL & $\mathbf{3 . 6 5}$ & Efficient \\
\hline
\end{tabular}

1-1.75 - not efficient; 1.75-2.5 - low efficiency; 2.5-3.25 - moderate efficiency; 3.25-4.0 - efficient

Results of the survey show that students think they are more efficient learners when taking down notes and outlines. They agree that it allows them to remember lessons better and organize their thoughts better. In every item of the said instrument, the students felt efficient because of using outlines. It made them feel that they were able to study their lessons and could remember them easily because of repeated exposure to the information.

Table 2. T-test for paired samples comparing 2 groups of students who took the subject

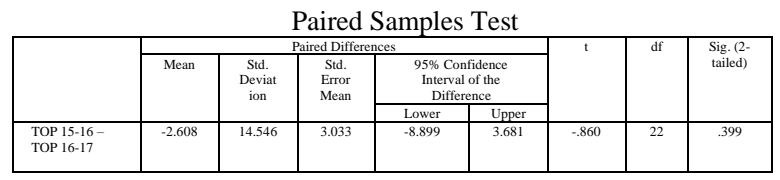

To support the descriptive result, a t-test of paired samples was conducted on the data composed of the students' grades. Based on the results, there is no significant difference between the grades of the students from batch 2015-2016 and batch 2016-2017. Therefore the hypothesis is rejected. The average of the students on the said subject is almost the same.

\section{Discussion}

Making an outline and taking notes allow the students to recall information better because they are exposed to it several times. They feel that they know a specific topic more when they get to encounter it often instead of just hearing it once during the discussion. Doing a lot of things in school also makes them feel that they know a lot about the subject matter. This was supported by the article that says note-taking or outlining results in better listening skills as well as recording ability [4]. The repeated exposure to the stimulus, which is the lesson, through listening or reading and then writing results in the storage of information in the long-term memory.

Efficiency pertains to a person's ability to accomplish something with less time and effort. It translates to a person's competence to perform something. The survey measured whether the students thought that outlining helped them in achieving higher grades and made studying easier. 
Participants of the study were interviewed about how using outlines and taking down notes affect their study habits. The students expressed how they felt motivated and efficient in studying. Based on the qualitative data gathered, they expressed feeling smart and looking smart when making outlines. They also felt like they were good students and they hoped that outlining would help them remember their lessons later during the exams.

The students in the study of Al-Ashkar [1] felt the same way about making outlines and using notetaking. They believed that it is effective in helping them improve both listening and writing skills. The survey used in the study gained the same results and showed how students valued notetaking as a tool for studying efficiently.

The results of inferential statistics used suggest that there is no significant difference between the two groups. The reason for this could be attributed to other study habits and classroom strategies for helping students to learn. Batch 2015 was not required to have an outline of their lessons but some of them are also doing it. Also, it is common among students to just copy the outline of their classmates, defeating the purpose of them being able to read before writing. Plus, according to the different theories of learning, there are different modes of processing information. Some students are visual and would tend to remember drawings, charts, and graphs. Some students are auditory and would rather listen than look. And also, some kinesthetic learners need to experience things to keep them in mind [2].

The motivation of the students to learn could also be considered as an extraneous variable. This is based on the interview conducted with some of the students. The grades of the students in Theories of Personality were the data used in this study. The subject is completely theoretical and contains a lot of concepts and facts based on informal interviews that are very difficult to study. The theories are closely related to each other and often very confusing. One concept may be defined in varied ways by different theorists. Admittedly, some students agreed that outlining is effective, however, due to lack of time they were unable to write proper lesson outlines. Poor handwriting is also a factor that demotivates them from using their outlines when studying.

It could be noted that in the study of Beck [2], students who used laptops for notetaking showed no advantage against students who made outlines by hand. There was no significant difference in their average scores on a test. The same study also concluded that the number of samples, as well as the subject being studied, could have been extraneous variables that affected the results.

\section{Recommendation}

The results of the study show that the students know and value making outlines as an important study habit because it makes them feel more efficient in studying. However, since there was no significant difference in the academic performance of the two groups, outlining could not be directly attributed to higher academic performance. There is a need to use another type of teaching strategy and to promote other types of study habits that could help the students to learn better. The department may coordinate with the Guidance, Counseling, and Health Office to reinforce their program on Study Habits through guidance classes. If making outlines or notetaking would be prescribed as a class requirement, the students should be equipped with how to use generative notetaking instead of simply doing it for the sake of subject completion.

\section{Conclusion}

Making outlines contribute to the efficiency of the students when it comes to studying. Using this study habit alone is not enough to increase the academic performance of the students. The course being studied may require different forms of study habits. There is a need to explore other ways of motivating the students to learn depending on the courses being taken.

\section{References}

[1] Al-Ashkar, B-E. (2014). The Influence of Note-taking Strategy on Improving Students' Academic Achievement from English and TEFL Majors' Perspectives at An-Najah National University. [Unpublished Master's Thesis]. An-Najah National University. Retrieved November 2020, from https://scholar.najah.edu/sites/default/files/Bayan\%20AlAshkar.pdf. (Access Date: 30 November 2020).

[2] Beck, K.M. (2014). Note Taking Effectiveness in the Modern Classroom. The Compass: Vol. 1 : Iss. 1, Article 9. Retrieved November 2020, from https://scholarworks.arcadia. edu/thecompass/vol1/iss1/9. (Access Date: 30 November 2020).

[3] Carnegie Mellon University. (n.d.). Why are students coming into college poorly prepared to write? Eberly Center. Retrieved November 2020, from https://www.cmu.edu/ teaching/designteach/teach/instructionalstrategies/writing/poor lyprepared.html. (Access Date: 30 November 2020).

[4] Chen, PH (2013). The Effects of College Students' In-Class and After-Class Lecture Note-Taking on Academic Performance. Asia-Pacific Edu Res 22, 173-180. Retrieved November 2020, from https://doi.org/10.1007/s40299-0120010-8, https://link.springer.com/article/10.1007/s40299-012 -0010-8. (Access Date: 30 November 2020).

[5] Doubek, J. (2016). Attention, Students: Put Your Laptops Away. NPR. Retrieved January 2018; from https://www.npr.org/2016/04/17/474525392/attention-students -put-your-laptops-away\#: :text=Live\%20Sessions-,Taking 
$\% 20$ Notes\%20By\%20Hand\%20May\%20Be\%20Better\%20Th an $\% 20$ Digitally $\% 2 \mathrm{C} \% 20$ Researchers,re\%20forced $\% 20$ to $\% 20$ slow\%20down. (Access Date: 6 March 2018).

[6] Haghverdi, H.R., Biria, R., and Karimi, L. (2010). Notetaking strategies and academic achievement. Journal of Language and Linguistic Studies, Vol. 6, No. 1. Retrieved November 2020, from https://www.jlls.org/index.php/jlls/artic le/view/91. (Access Date: 30 November 2020).

[7] Hansen, R. (n.d.). 10 Tips for getting good (or better) grades. Retrieved November 2020, from https://www.livecareer.com/resources/careers/recentgrads/getting-better-grades. (Access Date: 30 November 2020).

[8] MindTools.(n.d.). VAK Learning Styles: Understanding How Team Members Learn. Retrieved December 2017; from https://www.mindtools.com/pages/article/vak-learningstyles.htm. (Access Date: 6 March 2018).

[9] Missouri State University. (n.d.). Outlining Method for Note Taking. Retrieved November 2020, from https://www.missouristate.edu/assets/busadv/p.24.pdf. (Access Date: 30 November 2020).

[10] Mueller, PA., Oppenheimer, DM. (2014). The Pen Is Mightier Than the Keyboard: Advantages of Longhand Over Laptop Note Taking. Association of Psychological Science, Vol, 25, Issue 6. Retrieved November 2020, from https://doi. org/10.1177/0956797614524581. (Access Date: 30 November 2020).

[11] Purdue Online Writing Lab. (n.d.). Why and How to Create a Useful Outline. Retrieved November 2020, from https://owl.purdue.edu/owl/general_writing/the_writing_proce ss/developing_an_outline/how_to_outline.html. (Access Date: 30 November 2020)

[12] Smith, N. (2017). What are the Benefits of Using An Outline When Writing? Retrieved December 2017; from https://classroom.synonym.com/benefits-using-outline-writing -27307.html. (Access Date: 6 March 2018).

[13] Warren, J. (2017). 10 Reasons why you should make your own outline. Retrieved November 2020, from https://lawschool toolbox.com/10-reasons-why-you-should-make-your-own-outl ine/. (Access Date: 30 November 2020). 